\title{
On $\alpha-\psi$-Meir-Keeler contractive mappings
}

\author{
Erdal Karapınar ${ }^{1}$, Poom Kumam ${ }^{2^{*}}$ and Peyman Salimi ${ }^{3}$
}

\author{
${ }^{*}$ Correspondence: \\ poom.kum@kmutt.ac.th; \\ poom.kumam@mail.kmutt.ac.th \\ 2 Department of Mathematics, \\ Faculty of Science, King Mongkut's \\ University of Technology Thonburi, \\ Bangkok, 10140, Thailand \\ Full list of author information is \\ available at the end of the article
}

\begin{abstract}
In this paper, we introduce the notion of $\alpha-\psi$-Meir-Keeler contractive mappings via a triangular $\alpha$-admissible mapping. We discuss the existence and uniqueness of a fixed point of such a mapping in the setting of complete metric spaces. We state a number of examples to illustrate our results.
\end{abstract}

MSC: $46 \mathrm{~N} 40 ; 47 \mathrm{H} 10 ; 54 \mathrm{H} 25 ; 46 \mathrm{~T} 99$

Keywords: Meir-Keeler contractive mappings; triangular $\alpha$-admissible mappings; fixed points

\section{Introduction and preliminaries}

Fixed-point theory is one of the most intriguing research fields in nonlinear analysis. The number of authors have published papers and have increased continuously in the last decades. The main reason for this involvement can be observed easily: Application potential. Fixed point theory has an application in many disciplines such as chemistry, physics, biology, computer science and many branches of mathematics. Banach contraction mapping principle or Banach fixed-point theorem is the most celebrated and pioneer result in this direction: In a complete metric space, each contraction mapping has a unique fixed point. Following Banach [1], many authors give various generalizations of this principle in various space (see e.g. [2-20]). One of the interesting results was given by Samet et al. [21] by defining $\alpha-\psi$-contractive mappings via admissible mappings, see also [22].

In this paper, we introduce an $\alpha-\psi$-Meir-Keeler contractive mapping in the setting of complete metric spaces via a triangular $\alpha$-admissible mapping. We prove the existence and uniqueness of a fixed point of such a mapping. We also consider a number of examples to illustrate our results.

Definition 1 Let $f: X \rightarrow X$ and $\alpha: X \times X \rightarrow(-\infty,+\infty)$. We say that $f$ is a triangular $\alpha$-admissible mapping if

(T1) $\alpha(x, y) \geq 1$ implies $\alpha(f x, f y) \geq 1, x, y \in X$,

(T2) $\left\{\begin{array}{l}\alpha(x, z) \geq 1, \\ \alpha(z, y) \geq 1,\end{array}\right.$ implies $\alpha(x, y) \geq 1, x, y, z \in X$.

Example 2 Let $X=\mathbb{R}, f x=\sqrt[3]{x}$ and $\alpha(x, y)=e^{x-y}$ then $f$ is a triangular $\alpha$-admissible mapping. Indeed, if $\alpha(x, y)=e^{x-y} \geq 1$ then $x \geq y$ which implies $f x \geq f y$. That is, $\alpha(f x, f y)=$ $e^{f x-f y} \geq 1$. Also, if $\left\{\begin{array}{l}\alpha(x, z) \geq 1, \\ \alpha(z, y) \geq 1\end{array}\right.$ then $\left\{\begin{array}{l}x-z \geq 0, \\ z-y \geq 0 .\end{array}\right.$ That is, $x-y \geq 0$ and so $\alpha(x, y)=e^{x-y} \geq 1$.

Example 3 Let $X=\mathbb{R}, f x=e^{x^{7}}$ and $\alpha(x, y)=\sqrt[5]{x-y}+1$. Hence, $f$ is a triangular $\alpha$ admissible mapping. Again, if $\alpha(x, y)=\sqrt[5]{x-y}+1 \geq 1$ then $x \geq y$ which implies $f x \geq f y$. That is, $\alpha(f x, f y) \geq 1$.

(c) 2013 Karapınar et al.; licensee Springer. This is an Open Access article distributed under the terms of the Creative Commons Attribution License (http://creativecommons.org/licenses/by/2.0), which permits unrestricted use, distribution, and reproduction in any medium, provided the original work is properly cited. 
Moreover, if $\left\{\begin{array}{l}\alpha(x, z) \geq 1 ; \\ \alpha(z, y) \geq 1,\end{array}\right.$ then $x-y \geq 0$, and hence, $\alpha(x, y) \geq 1$.

Example 4 Let $X=[0,+\infty), f x=x^{4}+\ln \left(x^{2}+1\right)$ and

$$
\alpha(x, y)=\frac{x^{3}}{1+x^{3}}-\frac{y^{3}}{y^{3}+1}+1 .
$$

Then $f$ is a triangular $\alpha$-admissible mapping. In fact, if

$$
\alpha(x, y)=\frac{x^{3}}{1+x^{3}}-\frac{y^{3}}{y^{3}+1}+1 \geq 1
$$

then $x \geq y$. Hence, $f x \geq f y$. That is, $\alpha(f x, f y) \geq 1$. Also,

$$
\begin{aligned}
\alpha(x, z)+\alpha(z, y) & =\frac{x^{3}}{1+x^{3}}-\frac{z^{3}}{z^{3}+1}+1+\frac{z^{3}}{1+z^{3}}-\frac{y^{3}}{y^{3}+1}+1 \\
& =\frac{x^{3}}{1+x^{3}}-\frac{y^{3}}{y^{3}+1}+2 \leq 2\left(\frac{x^{3}}{1+x^{3}}-\frac{y^{3}}{y^{3}+1}+1\right)=2 \alpha(x, y) .
\end{aligned}
$$

Thus, $\alpha(x, z)+\alpha(z, y) \leq 2 \alpha(x, y)$. Now, if $\left\{\begin{array}{l}\alpha(x, z) \geq 1 ; \\ \alpha(z, y) \geq 1,\end{array}\right.$ then $\alpha(x, y) \geq 1$.

Example 5 Let $X=\mathbb{R}, f x=x^{3}+\sqrt[7]{x}$ and $\alpha(x, y)=x^{5}-y^{5}+1$. Then $f$ is a triangular $\alpha$ admissible mapping.

Example 6 Let $X=[0,+\infty), f x=x^{2}+e^{x}$ and

$$
\alpha(x, y)= \begin{cases}1, & \text { if } x, y \in[0,1] \\ 0, & \text { otherwise }\end{cases}
$$

Hence, $f$ is a triangular $\alpha$-admissible mapping.

Lemma 7 Let $f$ be a triangular $\alpha$-admissible mapping. Assume that there exists $x_{0} \in X$ such that $\alpha\left(x_{0}, f x_{0}\right) \geq 1$. Define sequence $\left\{x_{n}\right\}$ by $x_{n}=f^{n} x_{0}$. Then

$$
\alpha\left(x_{m}, x_{n}\right) \geq 1 \text { for all } m, n \in \mathbb{N} \text { with } m<n
$$

Proof Since there exist $x_{0} \in X$ such that $\alpha\left(x_{0}, f x_{0}\right) \geq 1$ then from (T1), we deduce that $\alpha\left(x_{1}, x_{2}\right)=\alpha\left(f x_{0}, f^{2} x_{0}\right) \geq 1$. By continuing this process, we get

$$
\alpha\left(x_{n}, x_{n+1}\right) \geq 1 \quad \text { for all } n \in \mathbb{N} \cup 0 \text {. }
$$

Suppose that $m<n$. Since $\left\{\begin{array}{l}\alpha\left(x_{m}, x_{m+1}\right) \geq 1, \\ \alpha\left(x_{m+1}, x_{m+2}\right) \geq 1\end{array}\right.$, then from (T2) we have $\alpha\left(x_{m}, x_{m+2}\right) \geq 1$.

Again, since $\left\{\begin{array}{l}\alpha\left(x_{m}, x_{m+2}\right) \geq 1, \\ \alpha\left(x_{m+2}, x_{m+3}\right) \geq 1\end{array}\right.$ then we deduce $\alpha\left(x_{m}, x_{m+3}\right) \geq 1$.

By continuing this process, we get $\alpha\left(x_{m}, x_{n}\right) \geq 1$.

Denote with $\Psi$ the family of nondecreasing functions $\psi:[0,+\infty) \rightarrow[0,+\infty)$ continuous in $t=0$ such that

- $\psi(t)=0$ if and only if $t=0$,

- $\psi(t+s) \leq \psi(t)+\psi(s)$. 


\section{Main results}

Definition 8 Let $(X, d)$ be a metric space and $\psi \in \Psi$. Suppose that $f: X \rightarrow X$ is a triangular $\alpha$-admissible mapping satisfying the following condition: for each $\varepsilon>0$ there exists $\delta>0$ such that

$$
\varepsilon \leq \psi(d(x, y))<\varepsilon+\delta \quad \text { implies } \quad \alpha(x, y) \psi(d(f x, f y))<\varepsilon
$$

for all $x, y \in X$. Then $f$ is called an $\alpha-\psi$-Meir-Keeler contractive mapping.

Remark 9 Let $f$ be an $\alpha$ - $\psi$-Meir-Keeler contractive mapping. Then

$$
\alpha(x, y) \psi(d(f x, f y))<\psi(d(x, y))
$$

for all $x, y \in X$ when $x \neq y$. Also, if $x=y$ then $d(f x, f y)=0$. i.e.,

$$
\alpha(x, y) \psi(d(f x, f y)) \leq \psi(d(x, y))
$$

for all $x, y \in X$.

Theorem 10 Let $(X, d)$ be a complete metric space. Suppose that $f$ is a continuous $\alpha-\psi$ Meir-Keeler contractive mapping and that there exists $x_{0} \in X$ such that $\alpha\left(x_{0}, f x_{0}\right) \geq 1$, then $f$ has a fixed point.

Proof Let $x_{0} \in X$ and define a sequence $\left\{x_{n}\right\}$ by $x_{n}=f^{n} x_{0}$ for all $n \in \mathbb{N}$. If $x_{n_{0}}=x_{n_{0}+1}$ for some $n_{0} \in \mathbb{N} \cup\{0\}$, then obviously $f$ has a fixed point. Hence, we suppose that

$$
x_{n} \neq x_{n+1}
$$

for all $n \in \mathbb{N} \cup\{0\}$. We have $d\left(x_{n}, x_{n+1}\right)>0$ for all $n \in \mathbb{N} \cup\{0\}$. Now define $s_{n}=\psi\left(d\left(x_{n}, x_{n+1}\right)\right)$. By Remark 9, we deduce that for all $n \in \mathbb{N} \cup\{0\}$,

$$
\alpha\left(x_{n}, x_{n+1}\right) \psi\left(d\left(x_{n+1}, x_{n+2}\right)\right)=\alpha\left(x_{n}, x_{n+1}\right) \psi\left(d\left(f x_{n}, f x_{n+1}\right)\right)<\psi\left(d\left(x_{n}, x_{n+1}\right)\right) .
$$

Then by applying Lemma 7

$$
\psi\left(d\left(x_{n+1}, x_{n+2}\right)\right)<\psi\left(d\left(x_{n}, x_{n+1}\right)\right) .
$$

Hence, the sequence $\left\{s_{n}\right\}$ is decreasing in $\mathbb{R}_{+}$and so it is convergent to $s \in \mathbb{R}_{+}$. We will show that $s=0$. Suppose, to the contrary, that $s>0$. Hence, we have

$$
0<s<\psi\left(d\left(x_{n}, x_{n+1}\right)\right) \quad \text { for all } n \in \mathbb{N} \cup\{0\} \text {. }
$$

Let $\varepsilon=s>0$. Then by hypothesis, there exists a $\delta(\varepsilon)>0$ such that (2.1) holds. On the other hand, by the definition of $\varepsilon$, there exists $n_{0} \in \mathbb{N}$ such that

$$
\varepsilon<s_{n_{0}}=\psi\left(d\left(x_{n_{0}}, x_{n_{0}+1}\right)\right)<\varepsilon+\delta .
$$


Now by (2.1), we have

$$
\begin{aligned}
s_{n_{0}+1} & =\psi\left(d\left(x_{n_{0}+1}, x_{n_{0}+2}\right)\right) \leq \alpha\left(x_{n_{0}}, x_{n_{0}+1}\right) \psi\left(d\left(x_{n_{0}+1}, x_{n_{0}+2}\right)\right) \\
& =\alpha\left(x_{n_{0}}, x_{n_{0}+1}\right) \psi\left(d\left(f x_{n_{0}}, f x_{n_{0}+1}\right)\right)<\varepsilon=s
\end{aligned}
$$

which is a contradiction. Hence, $s=0$, that is, $\lim _{n \rightarrow+\infty} s_{n}=0$. Now, by the continuity of $\psi$ in $t=0$, we have $\lim _{n \rightarrow+\infty} d\left(x_{n}, x_{n+1}\right)=0$. For given $\varepsilon>0$, by the hypothesis, there exists a $\delta=\delta(\varepsilon)>0$ such that (2.1) holds. Without loss of generality, we assume $\delta<\varepsilon$. Since $s=0$, then there exists $N \in \mathbb{N}$ such that

$$
s_{n-1}=\psi\left(d\left(x_{n-1}, x_{n}\right)\right)<\delta, \quad \text { for all } n \geq N \text {. }
$$

We will prove that for any fixed $k \geq N_{0}$,

$$
\psi\left(d\left(x_{k}, x_{k+l}\right)\right) \leq \varepsilon, \quad \text { for all } l \in \mathbb{N}
$$

holds. Note that (2.5), by (2.4), holds for $l=1$. Suppose the condition (2.1) is satisfied for some $m \in \mathbb{N}$. For $l=m+1$, by $(2.4)$, we get

$$
\begin{aligned}
\psi\left(d\left(x_{k-1}, x_{k+m}\right)\right) & \leq \psi\left(d\left(x_{k-1}, x_{k}\right)+d\left(x_{k}, x_{k+m}\right)\right) \\
& \leq \psi\left(d\left(x_{k-1}, x_{k}\right)\right)+\psi\left(d\left(x_{k}, x_{k+m}\right)\right) \\
& <\varepsilon+\delta .
\end{aligned}
$$

If $\psi\left(d\left(x_{k-1}, x_{k+m}\right)\right) \geq \varepsilon$, then by $(2.1)$ we get

$$
\begin{aligned}
\psi\left(d\left(x_{k}, x_{k+m+1}\right)\right) & \leq \alpha\left(x_{k-1}, x_{k+m}\right) \psi\left(d\left(x_{k}, x_{k+m+1}\right)\right) \\
& =\alpha\left(x_{k}, x_{k+m+1}\right) \psi\left(d\left(f x_{k-1}, f x_{k+m}\right)\right)<\varepsilon
\end{aligned}
$$

and hence (2.5) holds.

If $\psi\left(d\left(x_{k-1}, x_{k+m}\right)\right)<\varepsilon$, by Remark 9, we get

$$
\psi\left(d\left(x_{k}, x_{k+m+1}\right)\right) \leq \alpha\left(x_{k-1}, x_{k+m}\right) \psi\left(d\left(x_{k}, x_{k+m+1}\right)\right) \leq \psi\left(d\left(x_{k-1}, x_{k+m}\right)\right)<\varepsilon .
$$

Consequently, (2.5) holds for $l=m+1$. Hence, $\psi\left(d\left(x_{k}, x_{k+l}\right)\right) \leq \varepsilon$ for all $k \geq N_{0}$ and $l \geq 1$, which means

$$
d\left(x_{n}, x_{m}\right)<\varepsilon, \quad \text { for all } m \geq n \geq N_{0} .
$$

Hence $\left\{x_{n}\right\}$ is a Cauchy sequence. Since $(X, d)$ is complete, there exists $z \in X$ such that $x_{n} \rightarrow z$ as $n \rightarrow \infty$. Now, since, $f$ is continuous then

$$
f z=f\left(\lim _{n \rightarrow \infty} x_{n}\right)=\lim _{n \rightarrow \infty} x_{n+1}=z
$$

that is, $f$ has a fixed point. 
Theorem 11 Let $(X, d)$ be a complete metric space and let $f$ be a $\alpha$ - $\psi$-Meir-Keeler contractive mapping. If the following conditions hold:

(i) there exists $x_{0} \in X$ such that $\alpha\left(x_{0}, f x_{0}\right) \geq 1$,

(ii) if $\left\{x_{n}\right\}$ is a sequence in $X$ such that $\alpha\left(x_{n}, x_{n+1}\right) \geq 1$ for all $n$ and $x_{n} \rightarrow x$ as $n \rightarrow+\infty$, then $\alpha\left(x_{n}, x\right) \geq 1$ for all $n$.

Then $f$ has a fixed point.

Proof Following the proof of the Theorem 10, we say that $\alpha\left(x_{n}, x_{n+1}\right) \geq 1$ for all $n \in \mathbb{N} \cup\{0\}$ and that there exist $z \in X$ such that $x_{n} \rightarrow z$ as $n \rightarrow+\infty$. Hence, from (ii) $\alpha\left(x_{n}, z\right) \geq 1$. By Remark 9, we have

$$
\begin{aligned}
\psi(d(f z, z)) & \leq \psi\left(d\left(f z, f x_{n}\right)+d\left(f x_{n}, z\right)\right) \\
& \leq \psi\left(d\left(f z, f x_{n}\right)\right)+\psi\left(d\left(f x_{n}, z\right)\right) \\
& \leq \alpha\left(x_{n}, z\right) \psi\left(d\left(f z, f x_{n}\right)\right)+\psi\left(d\left(f x_{n}, z\right)\right) \\
& \leq \psi\left(d\left(z, x_{n}\right)\right)+\psi\left(d\left(x_{n+1}, z\right)\right) .
\end{aligned}
$$

By taking limit as $n \rightarrow+\infty$, in the above inequality, we get $\psi(d(f z, z)) \leq 0$, that is, $d(f z, z)=0$. Hence, $f z=z$.

Next, we give some examples to validate our main result.

Example 12 Let $X=[0, \infty)$ and $d(x, y)=|x-y|$ be a metric on $X$. Define $f: X \rightarrow X$ by

$$
f x=\left\{\begin{array}{ll}
\frac{x^{2}}{4}, & \text { if } x \in[0,1], \\
2 x, & \text { if } x \in(1, \infty),
\end{array} \text { and } \quad \alpha(x, y)= \begin{cases}1, & \text { if } x, y \in[0,1] \\
-1, & \text { otherwise }\end{cases}\right.
$$

and $\psi(t)=\frac{1}{4} t$. Clearly, $(X, d)$ is a complete metric space. We show that $f$ is a triangular $\alpha$-admissible mapping. Let $x, y \in X$, if $\alpha(x, y) \geq 1$ then $x, y \in[0,1]$. On the other hand, for all $x, y \in[0,1]$ we have $f x \leq 1$ and $f y \leq 1$. It follows that $\alpha(f x, f y) \geq 1$. Also, if $\alpha(x, z) \geq 1$ and $\alpha(z, y) \geq 1$ then $x, y, z \in[0,1]$ and hence, $\alpha(x, y) \geq 1$. Thus, the assertion holds by the same arguments. Notice that $\alpha(0, f 0) \geq 1$.

Now, if $\left\{x_{n}\right\}$ is a sequence in $X$ such that $\alpha\left(x_{n}, x_{n+1}\right) \geq 1$ for all $n \in \mathbb{N} \cup\{0\}$ and $x_{n} \rightarrow x$ as $n \rightarrow+\infty$, then $\left\{x_{n}\right\} \subset[0,1]$ and hence $x \in[0,1]$. This implies that $\alpha\left(x_{n}, x\right) \geq 1$ for all $n \in \mathbb{N} \cup\{0\}$. Let $x, y \in[0,1]$. Without loss of generality, take $x \leq y$. Then

$$
\begin{aligned}
& \psi(d(f x, f y))=\frac{y^{2}}{16}-\frac{x^{2}}{16}, \\
& \psi(d(x, y))=\frac{y}{4}-\frac{x}{4} .
\end{aligned}
$$

Clearly, by taking $\delta=\varepsilon$ the condition (2.1) holds. Otherwise, $\alpha(x, y)=-1$. Hence, for given $\varepsilon>0$ we have $\alpha(x, y) \psi(d(f x, f y)) \leq 0<\varepsilon$. Hence, conditions of Theorem 11 holds and $f$ has a fixed point. But, if $x, y \in(1, \infty)$ and

$$
\varepsilon \leq d(x, y)<\varepsilon+\delta
$$


where $\varepsilon>0$ and $\delta>0$. Then

$$
d(f x, f y)=2|x-y|=2 d(x, y) \geq d(x, y) \geq \varepsilon .
$$

That is, the Meir-Keeler theorem cannot applied for this example.

Example 13 Let $X=[0, \infty)$ and $d(x, y)=|x-y|$ be a metric on $X$. Define $f: X \rightarrow X$ by

$$
f x= \begin{cases}\frac{1}{2}(1-x), & \text { if } x \in[0,1], \\ \frac{\sqrt{4-x^{2}}}{2+\sin \left(x^{2}\right)}, & \text { if } x \in(1,2], \\ \frac{\sqrt[3]{x-2}}{x^{3}+1}, & \text { if } x \in(2, \infty)\end{cases}
$$

and $\psi(t)=\frac{1}{2} t$

$$
\alpha(x, y)= \begin{cases}1, & \text { if } x, y, z \in[0,1] \\ -1, & \text { otherwise }\end{cases}
$$

Let $x, y \in[0,1]$. Without loss of generality, take $x \leq y$. Then

$$
\begin{aligned}
& \psi(d(f x, f y))=\frac{1}{4}(y-x), \\
& \psi(d(x, y))=\frac{1}{2}(y-x) .
\end{aligned}
$$

Clearly, by taking $\delta=\varepsilon$ the condition (2.1) holds. Otherwise, $\alpha(x, y)=-1$. Hence, for given $\varepsilon>0$ we have $\alpha(x, y) \psi(d(f x, f y)) \leq 0<\varepsilon$. Hence, conditions of Theorem 11 holds and $f$ has a fixed point.

Denote with $\Psi_{s t}$ the family of strictly nondecreasing functions $\psi_{s t}:[0,+\infty) \rightarrow[0,+\infty)$ continuous in $t=0$ such that

- $\psi_{s t}(t)=0$ if and only if $t=0$,

- $\psi_{s t}(t+s) \leq \psi_{s t}(t)+\psi_{s t}(s)$.

Definition 14 Let $(X, d)$ be a metric space and $\psi_{s t} \in \Psi_{s t}$. Suppose that $f: X \rightarrow X$ is a triangular $\alpha$-admissible mapping satisfying the following condition: for each $\varepsilon>0$ there exists $\delta>0$ such that

$$
\varepsilon \leq \psi_{s t}(M(x, y))<\varepsilon+\delta \quad \text { implies } \quad \alpha(x, y) \psi_{s t}(d(f x, f y))<\varepsilon
$$

for all $x, y \in X$ where

$$
M(x, y)=\max \left\{d(x, y), d(f x, x), d(f y, y), \frac{1}{2}[d(f x, y)+d(x, f y)]\right\} .
$$

Then $f$ is called generalized an $\alpha-\psi_{s t}$-Meir-Keeler contractive mapping. 
Remark 15 Let $f$ be a generalized $\alpha-\psi_{s t}$-Meir-Keeler contractive mapping. Then

$$
\alpha(x, y) \psi_{s t}(d(f x, f y))<\psi_{s t}(M(x, y))
$$

for all $x, y \in X$ when $M(x, y)>0$. Also, if $M(x, y)=0$ then $x=y$ which implies $\psi(d(f x$, $f y))=0$, i.e.,

$$
\alpha(x, y) \psi_{s t}(d(f x, f y)) \leq \psi_{s t}(M(x, y))
$$

for all $x, y \in X$.

Proposition 16 Let $(X, d)$ be a metric space and $f: X \rightarrow X$ a generalized $\alpha-\psi_{s t}$-MeirKeeler contractive mapping, if there exists $x_{0} \in X$ such that $\alpha\left(x_{0}, f x_{0}\right) \geq 1$. Then $\lim _{n \rightarrow \infty} d\left(f^{n+1} x_{0}, f^{n} x_{0}\right)=0$.

Proof Define a sequence $\left\{x_{n}\right\}$ by $x_{n}=f^{n} x_{0}$ for all $n \in \mathbb{N}$. If $x_{n_{0}}=x_{n_{0}+1}$ for some $n_{0} \in \mathbb{N} \cup\{0\}$, then obviously $f$ has a fixed point. Hence, we suppose that

$$
x_{n} \neq x_{n+1}
$$

for all $n \in \mathbb{N} \cup\{0\}$. Then we have $M\left(x_{n+1}, x_{n}\right)>0$ for every $n \geq 0$. Then by Lemma 7 and Remark 15, we have

$$
\begin{aligned}
\psi_{s t}\left(d\left(x_{n+1}, x_{n+2}\right)\right) \leq & \alpha\left(x_{n}, x_{n+1}\right) \psi_{s t}\left(d\left(x_{n+1}, x_{n+2}\right)\right) \\
= & \alpha\left(x_{n}, x_{n+1}\right) \psi_{s t}\left(d\left(f x_{n}, f x_{n+1}\right)\right)<\psi_{s t}\left(M\left(x_{n}, x_{n+1}\right)\right) \\
= & \psi_{s t}\left(\operatorname { m a x } \left\{d\left(x_{n}, x_{n+1}\right), d\left(f x_{n}, x_{n}\right), d\left(f x_{n+1}, x_{n+1}\right),\right.\right. \\
& \left.\left.\frac{1}{2}\left[d\left(f x_{n}, x_{n+1}\right)+d\left(x_{n}, f x_{n+1}\right)\right]\right\}\right) \\
\leq & \psi_{s t}\left(\max \left\{d\left(x_{n}, x_{n+1}\right), d\left(x_{n+1}, x_{n+2}\right)\right\}\right) .
\end{aligned}
$$

Now, since $\psi_{s t}$ is strictly nondecreasing then, we get

$$
d\left(x_{n+2}, x_{n+1}\right)<\max \left\{d\left(x_{n+1}, x_{n}\right), d\left(x_{n+2}, x_{n+1}\right)\right\} .
$$

Hence, the case where

$$
\max \left\{d\left(x_{n+1}, x_{n}\right), d\left(x_{n+2}, x_{n+1}\right)\right\}=d\left(x_{n+2}, x_{n+1}\right)
$$

is not possible. Therefore, we deduce that

$$
d\left(x_{n+2}, x_{n+1}\right)<d\left(x_{n+1}, x_{n}\right)
$$

for all $n$. That is, $\left\{d\left(x_{n+1}, x_{n}\right)\right\}_{n=0}^{\infty}$ is a decreasing sequence in $\mathbb{R}_{+}$and it converges to $\varepsilon \in \mathbb{R}_{+}$, that is,

$$
\lim _{n \rightarrow \infty} \psi_{s t}\left(d\left(x_{n+1}, x_{n}\right)\right)=\lim _{n \rightarrow \infty} \psi_{s t}\left(M\left(x_{n+1}, x_{n}\right)\right)=\psi_{s t}(\varepsilon)
$$


Notice that $\varepsilon=\inf \left\{p\left(x_{n}, x_{n+1}\right): n \in \mathbb{N}\right\}$. Let us prove that $\varepsilon=0$. Suppose, to the contrary, that $\varepsilon>0$. Then $\psi(\varepsilon)>0$. Regarding (2.11) together with the assumption that $f$ is a generalized $\alpha-\psi_{s t}$-Meir-Keeler contractive mapping, for $\psi_{s t}(\varepsilon)$, there exists $\delta>0$ and a natural number $m$ such that

$$
\psi_{s t}(\varepsilon) \leq \psi_{s t}\left(M\left(x_{m}, x_{m+1}\right)\right)<\psi_{s t}(\varepsilon)+\delta
$$

implies that

$$
\begin{aligned}
\psi_{s t}\left(d\left(x_{m+1}, x_{m+2}\right)\right) & \leq \alpha\left(x_{m}, x_{m+1}\right) \psi_{s t}\left(d\left(x_{m+1}, x_{m+2}\right)\right) \\
& =\alpha\left(x_{m}, x_{m+1}\right) \psi_{s t}\left(d\left(f x_{m}, f x_{m+1}\right)\right)<\psi_{s t}(\varepsilon) .
\end{aligned}
$$

Now, since $\psi_{s t}$ is strictly nondecreasing then we get

$$
d\left(x_{m+2}, x_{m+1}\right)<\varepsilon
$$

which is a contradiction since $\varepsilon=\inf \left\{p\left(x_{n}, x_{n+1}\right): n \in \mathbb{N}\right\}$. Then $\varepsilon=0$ and so $\lim _{n \rightarrow \infty} d\left(x_{n+1}\right.$, $\left.x_{n}\right)=0$.

Theorem 17 Let $(X, d)$ be a complete metric space and $f: X \rightarrow X$ a orbitally continuous generalized $\alpha-\psi_{\text {st }}$-Meir-Keeler contractive mapping, if there exist $x_{0} \in X$ such that $\alpha\left(x_{0}, f x_{0}\right) \geq 1$. Then, $f$ has a fixed point.

Proof Define $x_{n+1}=f^{n+1} x_{0}$ for all $n \geq 0$. We want to prove that $\lim _{m, n \rightarrow \infty} d\left(x_{n}, x_{m}\right)=0$. If this is not, then there exist $\varepsilon>0$ and a subsequence $\left\{x_{n(i)}\right\}$ of $\left\{x_{n}\right\}$ such that

$$
d\left(x_{n(i)}, x_{n(i+1)}\right)>2 \varepsilon \text {. }
$$

For this $\varepsilon>0$, there exists $\delta>0$ such that $\varepsilon \leq \psi_{s t}(M(x, y))<\varepsilon+\delta$ implies that $\alpha(x, y) \psi_{s t}(d(f x, f y))<\varepsilon$. Put $r=\min \{\varepsilon, \delta\}$ and $s_{n}=d\left(x_{n}, x_{n+1}\right)$ for all $n \geq 1$. From Proposition 16, there exists $n_{0}$ such that

$$
s_{n}=d\left(x_{n}, x_{n+1}\right)<\frac{r}{4}
$$

for all $n \geq n_{0}$. Let $n(i)>n_{0}$. We get $n(i) \leq n(i+1)-1$. If $d\left(x_{n(i)}, x_{n(i+1)-1}\right) \leq \varepsilon+\frac{r}{2}$, then

$$
\begin{aligned}
d\left(x_{n(i)}, x_{n(i+1)}\right) & \leq d\left(x_{n(i)}, x_{n(i+1)-1}\right)+d\left(x_{n(i+1)-1}, x_{n(i+1)}\right) \\
& \leq d\left(x_{n(i)}, x_{n(i+1)-1}\right)+d\left(x_{n(i+1)-1}, x_{n(i+1)}\right) \\
& <\varepsilon+\frac{r}{2}+s_{n(i+1)-1}<\varepsilon+\frac{3 r}{4}<2 \varepsilon
\end{aligned}
$$

which contradicts the assumption (2.12). Therefore, there are values of $k$ such that $n(i) \leq$ $k \leq n(i+1)$ and $d\left(x_{n(i)}, x_{k}\right)>\varepsilon+\frac{r}{2}$. Now if $d\left(x_{n(i)}, x_{n(i)+1}\right) \geq \varepsilon+\frac{r}{2}$, then

$$
s_{n(i)}=d\left(x_{n(i)}, x_{n(i)+1}\right) \geq \varepsilon+\frac{r}{2}>r+\frac{r}{2}>\frac{r}{4}
$$


which is a contradiction with (2.13). Hence, there are values of $k$ with $n(i) \leq k \leq n(i+1)$ such that $d\left(x_{n(i)}, x_{k}\right)<\varepsilon+\frac{r}{2}$. Choose smallest integer $k$ with $k \geq n(i)$ such that $d\left(x_{n(i)}, x_{k}\right) \geq$ $\varepsilon+\frac{r}{2}$. Thus, $d\left(x_{n(i)}, x_{k-1}\right)<\varepsilon+\frac{r}{2}$ and so

$$
\begin{aligned}
d\left(x_{n(i)}, x_{k}\right) & \leq d\left(x_{n(i)}, x_{k-1}\right)+d\left(x_{k-1}, x_{k}\right) \\
& \leq d\left(x_{n(i)}, x_{k-1}\right)+d\left(x_{k-1}, x_{k}\right)<\varepsilon+\frac{r}{2}+\frac{r}{4}=\varepsilon+\frac{3 r}{4} .
\end{aligned}
$$

Now, we can choose a natural number $k$ satisfying $n(i) \leq k \leq n(i+1)$ such that

$$
\varepsilon+\frac{r}{2} \leq d\left(x_{n(i)}, x_{k}\right)<\varepsilon+\frac{3 r}{4} .
$$

Therefore, we obtain

$$
\begin{aligned}
& d\left(x_{n(i)}, x_{k}\right)<\varepsilon+\frac{3 r}{4}<\varepsilon+r, \\
& d\left(x_{n(i)}, x_{n(i)+1}\right)=d_{n(i)}<\frac{r}{4}<\varepsilon+r,
\end{aligned}
$$

and

$$
d\left(x_{k}, x_{k+1}\right)=d_{k}<\frac{r}{4}<\varepsilon+r .
$$

Thus, we have

$$
\begin{aligned}
\frac{1}{2} & {\left[d\left(x_{n(i)}, x_{k+1}\right)+d\left(x_{n(i)+1}, x_{k}\right)\right] } \\
& \leq \frac{1}{2}\left[d\left(x_{n(i)}, x_{k}\right)+d\left(x_{k}, x_{k+1}\right)+d\left(x_{n(i)+1}, x_{n(i)}\right)+d\left(x_{n(i)}, x_{k}\right)\right] \\
& \leq \frac{1}{2}\left[d\left(x_{n(i)}, x_{k}\right)+d\left(x_{k}, x_{k+1}\right)+d\left(x_{n(i)+1}, x_{n(i)}\right)+d\left(x_{n(i)}, x_{k}\right)\right] \\
& =d\left(x_{n(i)}, x_{k}\right)+\frac{1}{2}\left[s_{k}+s_{n(i)}\right] \\
& <\varepsilon+\frac{3 r}{4}+\frac{1}{2}\left[\frac{r}{4}+\frac{r}{4}\right]=\varepsilon+r .
\end{aligned}
$$

Now, the inequalities (2.15)-(2.18) imply that $M\left(x_{n(i)}, x_{k}\right)<\varepsilon+r \leq \varepsilon+\delta$ and so $\psi_{s t}\left(M\left(x_{n(i)}\right.\right.$, $\left.\left.x_{k}\right)\right)<\psi_{s t}(\varepsilon+\delta) \leq \psi_{s t}(\varepsilon)+\psi_{s t}(\delta)$ the fact that $f$ is a generalized $\alpha-\psi_{s t}$-Meir-Keeler contractive mapping yields that,

$$
d\left(x_{n(i)+1}, x_{k+1}\right) \leq \alpha\left(x_{n(i)}, x_{k}\right) \psi_{s t}\left(d\left(x_{n(i)+1}, x_{k+1}\right)\right)<\psi_{s t}(\varepsilon) .
$$

Then $d\left(x_{n(i)+1}, x_{k+1}\right)<\varepsilon$. We deduce,

$$
\begin{aligned}
d\left(f^{n(i)} x_{0}, f^{k} x_{0}\right) & \leq d\left(f^{n(i)} x_{0}, f^{n(i)+1} x_{0}\right)+d\left(f^{n(i)+1} x_{0}, f^{k} x_{0}\right) \\
& \leq d\left(f^{n(i)} x_{0}, f^{n(i)+1} x_{0}\right)+d\left(f^{n(i)+1} x_{0}, f^{k} x_{0}\right) \\
& \leq d\left(f^{n(i)} x_{0}, f^{n(i)+1} x_{0}\right)+d\left(f^{n(i)+1} x_{0}, f^{k+1} x_{0}\right)+d\left(f^{k+1} x_{0}, f^{k} x_{0}\right) .
\end{aligned}
$$


Hence, from this with (2.14), (2.16) and (2.17), we obtain

$$
\begin{aligned}
d\left(x_{n(i)+1}, x_{k+1}\right) & \geq d\left(x_{n(i)}, x_{k}\right)-d\left(x_{n(i)}, x_{n(i)+1}\right)-d\left(x_{k}, x_{k+1}\right) \\
& >\varepsilon+\frac{r}{2}-\frac{r}{4}-\frac{r}{4}=\varepsilon,
\end{aligned}
$$

which is a contradiction. We obtained that $\lim _{m, n \rightarrow \infty} d\left(x_{n}, x_{m}\right)=0$ and so $\left\{x_{n}=f^{n} x_{0}\right\}$ is a Cauchy sequence. Since, $X$ is complete, then there exists $z \in X$ such that $f^{n} x_{0} \rightarrow z$ as $n \rightarrow \infty$. Now, since $f$ is orbitally continuous, then $z=f z$.

Example 18 Let $X=[0, \infty)$ and $d(x, y)=|x-y|$ be a metric on $X$. Define $f: X \rightarrow X$ by

$$
f x= \begin{cases}\frac{x^{2}}{8}, & \text { if } x \in[0,1] \\ \frac{1}{2}+\ln x, & \text { if } x \in(1, \infty)\end{cases}
$$

and $\psi_{s t}(t)=\frac{1}{2} t$

$$
\alpha(x, y)= \begin{cases}1, & \text { if } x, y \in[0,1] \\ 0, & \text { otherwise }\end{cases}
$$

Clearly, $f$ is a triangular $\alpha$-admissible mapping and orbitally continuous. Let $x, y \in[0,1]$. Without loss of generality, take $x \leq y$. Then

$$
\begin{aligned}
& \psi_{s t}(d(f x, f y))=\frac{y^{2}}{16}-\frac{x^{2}}{16} \\
& \psi_{s t}(M(x, y))=\psi_{s t}\left(\max \left\{y-x, x-\frac{x^{2}}{8}, y-\frac{y^{2}}{8}\right\}\right)=\max \left\{\frac{y}{2}-\frac{x}{2}, \frac{x}{2}-\frac{x^{2}}{16}, \frac{y}{2}-\frac{y^{2}}{16}\right\} .
\end{aligned}
$$

Clearly, by taking $\delta=3 \varepsilon$ the condition (2.8) holds. Otherwise, $\alpha(x, y)=0$. Hence, for given $\varepsilon>0$, we have $0=\alpha(x, y) \psi_{s t}(d(f x, f y))<\varepsilon$. Hence, condition of Theorem 17 is held and $f$ has a fixed point.

Theorem 19 Assume that all the hypotheses of Theorem 10 (11 and 17) hold. Adding the following conditions:

(iii) for all $x \neq y \in X$ there exists $v \in X$ such that $\alpha(x, v) \geq 1$ and $\alpha(v, y) \geq 1$, we obtain the uniqueness of the fixed point off.

Proof Suppose that $z$ and $z^{*}$ are two fixed points of $f$ such that $z \neq z^{*}$. Then $\alpha(z, v) \geq 1$ and $\alpha\left(v, z^{*}\right) \geq 1$. Hence, from (T2), we have $\alpha\left(z, z^{*}\right) \geq 1$. Now, by Remark 9 , we get

$$
d\left(z, z^{*}\right)=d\left(f z, f z^{*}\right) \leq \alpha\left(z, z^{*}\right) d\left(f z, f z^{*}\right)<d\left(z, z^{*}\right)
$$

which is a contradiction and so $z=z^{*}$. Similarly, for Theorem 17 , we can observe that $f$ has a unique fixed point.

We can obtain the following corollaries intermediately. 
Corollary 20 Let $(X, d)$ be a complete metric space and $f: X \rightarrow X$ is self-mapping. Suppose that for each $\varepsilon>0$, there exists $\delta>0$ such that

$$
\varepsilon \leq \psi(d(x, y))<\varepsilon+\delta \quad \text { implies } \quad \psi(d(f x, f y))<\frac{\varepsilon}{L},
$$

where $\psi \in \Psi$ and $L \geq 1$. Then $f$ has a unique fixed points.

Corollary 21 Let $(X, d)$ be a complete metric space and $f: X \rightarrow X$ a orbitally continuous self-mapping. Suppose that for each $\varepsilon>0$ there exists $\delta>0$ such that

$$
\varepsilon \leq \psi_{s t}(M(x, y))<\varepsilon+\delta \quad \text { implies } \quad \psi_{s t}(d(f x, f y))<\frac{\varepsilon}{L},
$$

where $\psi_{s t} \in \Psi_{s t}, L \geq 1$ and

$$
M(x, y)=\max \left\{d(x, y), d(f x, x), d(f y, y), \frac{1}{2}[d(f x, y)+d(x, f y)]\right\} .
$$

Then $f$ has unique fixed points.

\section{Competing interests}

The authors declare that they have no competing interests.

\section{Authors' contributions}

All authors contributed equally and significantly in writing this paper. All authors read and approved the final manuscript.

\section{Author details}

${ }^{1}$ Department of Mathematics, Atilim University, Incek, Ankara, 06836, Turkey. ${ }^{2}$ Department of Mathematics, Faculty of Science, King Mongkut's University of Technology Thonburi, Bangkok, 10140, Thailand. ${ }^{3}$ Department of Mathematics, Astara Branch, Islamic Azad University, Astara, Iran.

\section{Acknowledgements}

The authors would like to thank the referees for their valuable comments and suggestions. Also, the second author would like to thank the Commission on Higher Education, the Thailand Research Fund and the King Mongkut's University of Technology Thonburi (Grant No. MRG5580213) for financial support during the preparation of this manuscript. The third author is thankful for support of Astara Branch, Islamic Azad University, during this research.

\section{Received: 23 December 2012 Accepted: 27 March 2013 Published: 12 April 2013}

\section{References}

1. Banach, S: Sur les opérations dans les ensembles abstraits et leur application aux equations itegrales. Fundam. Math. 3, 133-181 (1922)

2. Berinde, V: General constructive fixed point theorems for Ciric-type almost contractions in metric spaces. Carpath. J. Math. 24(2), 10-19 (2008)

3. Boyd, DW, Wong, JSW: On nonlinear contractions. Proc. Am. Math. Soc. 20, 458-464 (1969)

4. Chatterjea, SK: Fixed point theorems. C. R. Acad. Bulgare Sci. 25, 727-730 (1972)

5. Ćirić, L, Samet, B, Aydi, H, Vetro, C: Common fixed points of generalized contractions on partial metric spaces and an application. Appl. Math. Comput. 218, 2398-2406 (2011)

6. Edelstein, M: On fixed points and periodic points under contraction mappings. J. Lond. Math. Soc. 37, 74-79 (1962)

7. Hardy, GC, Rogers, T: A generalization of fixed point theorem of S. Reich. Can. Math. Bull. 16, $201-206$ (1973)

8. Holmes, RD: On fixed and periodic points under sets of mappings. Can. Math. Bull. 12, 813-822 (1969)

9. Jaggi, DS: Some unique fixed point theorems. Indian J. Pure Appl. Math. 8(2), 223-230 (1977)

10. Kannan, R: Some results on fixed points-II. Am. Math. Mon. 76, 71-76 (1969)

11. Karapinar, E: Fixed point theory for cyclic weak $\phi$-contraction. Appl. Math. Lett. 24, 822-825 (2011)

12. Karapınar, E: Weak $\phi$-contraction on partial metric spaces. J. Comput. Anal. Appl. 14(2), 206-210 (2012)

13. Karapinar, E, Erhan, IM: Fixed point theorems for operators on partial metric spaces. Appl. Math. Lett. 24, 1894-1899 (2011)

14. Karapınar, E: Generalizations of Caristi Kirk's theorem on partial metric spaces. Fixed Point Theory Appl. 2011, 4 (2011) doi:10.1186/1687-1812-2011-4

15. Karapınar, E: Some nonunique fixed point theorems of Ciric type on cone metric spaces. Abstr. Appl. Anal. 2010, Article ID 123094 (2010)

16. Karapınar, E: Fixed point theorems in cone Banach spaces. Fixed Point Theory Appl. 2009, Article ID 609281 (2009)

17. Karapınar, E, Yuksel, U: Some common fixed point theorems in partial metric spaces. J. Appl. Math. 2011, Article ID 263621 (2011) 
18. Karapınar, E: A note on common fixed point theorems in partial metric spaces. Miskolc Math. Notes 12(2), 185-191 (2011)

19. Kirk, WA, Srinavasan, PS, Veeramani, P: Fixed points for mapping satisfying cyclical contractive conditions. Fixed Point Theory Appl. 4, 79-89 (2003)

20. Reich, S: Some remarks concerning contraction mappings. Can. Math. Bull. 14, 121-124 (1971)

21. Samet, B, Vetro, C, Vetro, P: Fixed point theorem for $\alpha-\psi$ contractive type mappings. Nonlinear Anal. 75, 2154-2165 (2012)

22. Karapinar, E, Samet, B: Generalized $(\alpha-\psi)$ contractive type mappings and related fixed point theorems with applications. Abstr. Appl. Anal. 2012, Article ID 793486 (2012)

doi:10.1186/1687-1812-2013-94

Cite this article as: Karapınar et al.: On $\alpha$ - $\psi$-Meir-Keeler contractive mappings. Fixed Point Theory and Applications 2013 2013:94.

Submit your manuscript to a SpringerOpen ${ }^{\circ}$ journal and benefit from:

- Convenient online submission

Rigorous peer review

- Immediate publication on acceptance

- Open access: articles freely available online

- High visibility within the field

- Retaining the copyright to your article

Submit your next manuscript at $>$ springeropen.com 